\title{
Intense Exercise in the Quality of Life of Breast Cancer Survivors: A Meta-Analysis
}

\author{
Paulo Francisco de Almeida Neto ${ }^{1,2,3 *}$, Erenice Conceição de Almeida Barbosa ${ }^{3}$, \\ Karoline Queiroz Martins Almeida de Araújo 1,3,5, Tatianny de Macêdo Cesário1, \\ Brunna Rafaella do Carmo Silva1, Thiago Gil Vieira de Figueiredo Lima1, Nelson Carvas Júnior ${ }^{4}$, \\ Ana Carla Gomes Canário1,3
}

\author{
${ }^{1}$ Federal University of Rio Grande do Norte, UFRN, Natal, RN, Brazil \\ ${ }^{2}$ Brazilian Society of Clinical Oncology, SBOC, São Paulo, SP, Brazil \\ ${ }^{3}$ Mauricio of Nassau University Center, UNINASSA, Natal, RN, Brazil \\ ${ }^{4}$ Institute of Medical Assistance to the state public servant, IAMSPE, São Paulo, SP, Brazil \\ ${ }^{5}$ Federal University of Paraíba, UFPB, João Pessoa, PB, Brazil \\ Email: *paulojitte@ufrn.edu.br, *paulo220911@hotmail.com
}

How to cite this paper: de Almeida Neto, P.F., de Almeida Barbosa, E.C., de Araújo, K.Q.M.A., de Macêdo Cesário, T., do Carmo Silva, B.R., de Figueiredo Lima, T.G.V., Júnior, N.C. and Canário, A.C.G. (2019) Intense Exercise in the Quality of Life of Breast Cancer Survivors: A Meta-Analysis. Journal of Cancer Therapy, 10, 895-907. https://doi.org/10.4236/jct.2019.1012076

Received: October 23, 2019

Accepted: December 6, 2019

Published: December 9, 2019

Copyright $\odot 2019$ by author(s) and Scientific Research Publishing Inc. This work is licensed under the Creative Commons Attribution-NonCommercial International License (CC BY-NC 4.0).

http://creativecommons.org/licenses/by-nc/4.0/ cc) (i) (8) Open Access

\begin{abstract}
The treatment of breast cancer $(\mathrm{BC})$ leaves emotional and functional sequels affecting the quality of life (QOL) of the survivors. We aim to investigate, intense exercises in the rehabilitation of BC survivors. Using the systematic search model in the PubMed databases; Lilacs Bireme and Scielo. Meta-Analysis used the Meta package implemented in software R (version 3.3.2) $\mathrm{p}<0.05$. We selected 29 articles, and after reading in the Integra, we excluded 27 texts being included in the meta-analysis only 2 . In the QOL, the heterogeneity in the emotional function showed a difference of $75 \%$, in the social function $36 \%$ and in the physics $32 \%$. Using intense exercises in BC survivors during rehabilitation improves overall QOL, muscle structure, and preserves functional capacity.
\end{abstract}

\section{Keywords}

Breast Cancer, High-Intensity Exercises, High-Intensity Intermittent Exercise, Women's Health

\section{Introduction}

Breast cancer (BC) is a malignant neoplasm regarded as a chronic degenerative disease that mainly affects women [1]. In Brazil, it is the first cause of death among this population. The risk of developing this cancer throughout life is one in seventeen Brazilian women, and two thirds of the cases occur after meno- 
pause and $15 \%$ in women before 40 years of age. It is noteworthy that at least one third of new cases of cancer occurring in the world, annually, could be avoided [2].

The impact of the diagnosis of this disease and the treatment process generates serious consequences that may be temporary or permanent in woman's lives [3]. For every process whether it is conservative or not (with surgical procedure) can cause important decreases in self-esteem, limitations of the physical capacity of the upper limb due to the presence of lymphedema, and also the change of the tactile sensation of the sinus after Its reconstruction that can affect the femininity and performance of motherhood [4].

On the other hand, studies indicate that in a clinical routine it is possible to aggregate and develop the regular practice of physical exercises, especially in order to prevent and mitigate the symptoms resulting from the treatment. As a consequence, there are also improvements in cardiorespiratory and functional capacity [4] [5] [6]. According to the World Cancer Research Fund [5], the regular practice of physical exercise is considered a protective factor for the postmenopausal BC, however, despite the efficacy of the practice of physical exercise in the treatment of breast cancer to be widely known yet there is no a consensus on the exact prescription of the type, intensity, duration and method most appropriate for women who experience the treatment of BC.

The literature is still inconsistent, although there is strong evidence on the important health contributions brought by a physically active body [8]. This is probably due to the fact that both the complexity of the disease and the enormous heterogeneity of existing training exercises and protocols, which end up hindering such recommendations [9]. In general, the literature argues that during the recovery process, which occurs after the treatment of chemotherapy, radiotherapy and post-mastectomy surgery, physical exercise acts by increasing the adaptability of the muscular and cardiac functional capacity of women undergoing these processes [10]. What is extremely important since a sedentary lifestyle at this stage can cause an additional decline in functional capacity and should be avoided as much as possible [11] [12].

The recommendation most commonly used in the prescription of exercises in the post-treatment phase, are interventions of resistance exercises with low loads, especially in case of lymphedema after cancer and with mild intensities, performing only movements as a function that is closer to everyday life; Initially should prioritize exercises that require less strength or involvement of the pectoral muscles and gradually increase both the frequency and complexity according to the carrying capacity of these women [13] [14]. However, the use of exercises with higher loads and intensities has also shown effective results. The exercises promote improvement of body composition, endurance, muscular strength, flexibility and improvement of cardiorespiratory fitness [6]-[15].

In view of the above, this article aimed to produce a bibliographic study, of a systematic review with meta-analysis, that would bring together the main literary data that were produced up to the present day on the benefits of the use of 
high Load or high intensity in women surviving breast cancer, in order to identify the positive effects of this type of intervention.

\section{Methods}

\subsection{Research and Strategy}

This systematic review with meta-analysis is registered at the International Prospective Register of Systematic Reviews (PROSPERO), under the ID: CRD42019107397. The search for the literature was performed exclusively on the electronic research platforms, between January and August of 2017, in Portuguese, English and Spanish. The bases selected were: PubMed, Lilacs, Bireme and Scielo and none of them was used a time interval defined for the search of the articles. One year later in August 2019 in order to verify the emergence of new publications, the searches were performed again following the same procedures, and there were no differences in the results in relation to the searches of 2017.

In the investigation process, the advanced search tool was used during the searches and when available in the database, the filter for clinical trials was used. The following controlled descriptors were used: Breast cancer, high-intensity exercises, exercises and their respective synonyms were used for searches in PubMed; and the descriptors: Câncer de mama, Treinamento intervalado de alta intensidade, Exercícioand its synonyms for the searches in the other databases cited. Among the descriptors and their synonyms were used the Boolean operators $O R$ and $A N D$ as shown in Figure 1.

\subsection{Selection of Studies}

To construct this systematic review with meta-analysis, the evaluation of the eligibility of the studies was performed independently by two researchers. First, the studies were considered for inclusion based on the titles and abstracts and, secondly, the full text, where reports were examined for the fulfillment of the selection criteria. Any disagreement about the inclusion of the studies was resolved by discussion among the researchers; if necessary, a third person should be consulted to reach the consensus. The eligibility criteria used for the studies were: 1) The sample was composed only of women who survived breast cancer; 2) Use only physical exercises in their interventions; 3) Be a randomized clinical trial. They were excluded from this meta-analysis: 1) Studies comparing drug interventions and those who used the drug intervention in parallel with physical exercise.

\subsection{Bias Risk Assessment}

The evaluation of the risk of bias was performed by seven researchers separately, manually and with the succinct help of the free digital tool: Robot Reviewer Report (Available at $<$ https://robot-reviewer.vortext.systems/ $>$ ). The results of the evaluations were optimized and discussed by all authors until they reached the final product exposed below in Figure 2. 


\section{Database}

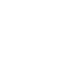<smiles>[I-]</smiles>

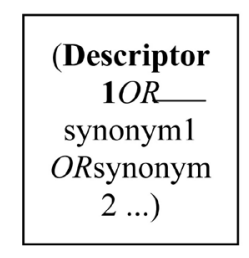

\begin{tabular}{|c|}
\hline (Descriptor \\
2ORsynony \\
$\mathrm{m} 1$ \\
ORsynonym \\
2 ...) \\
\hline
\end{tabular}

(Descriptor 3ORsynonym 1

ORsynonym $2 \ldots)$

Figure 1. Strategy of selection of studies.

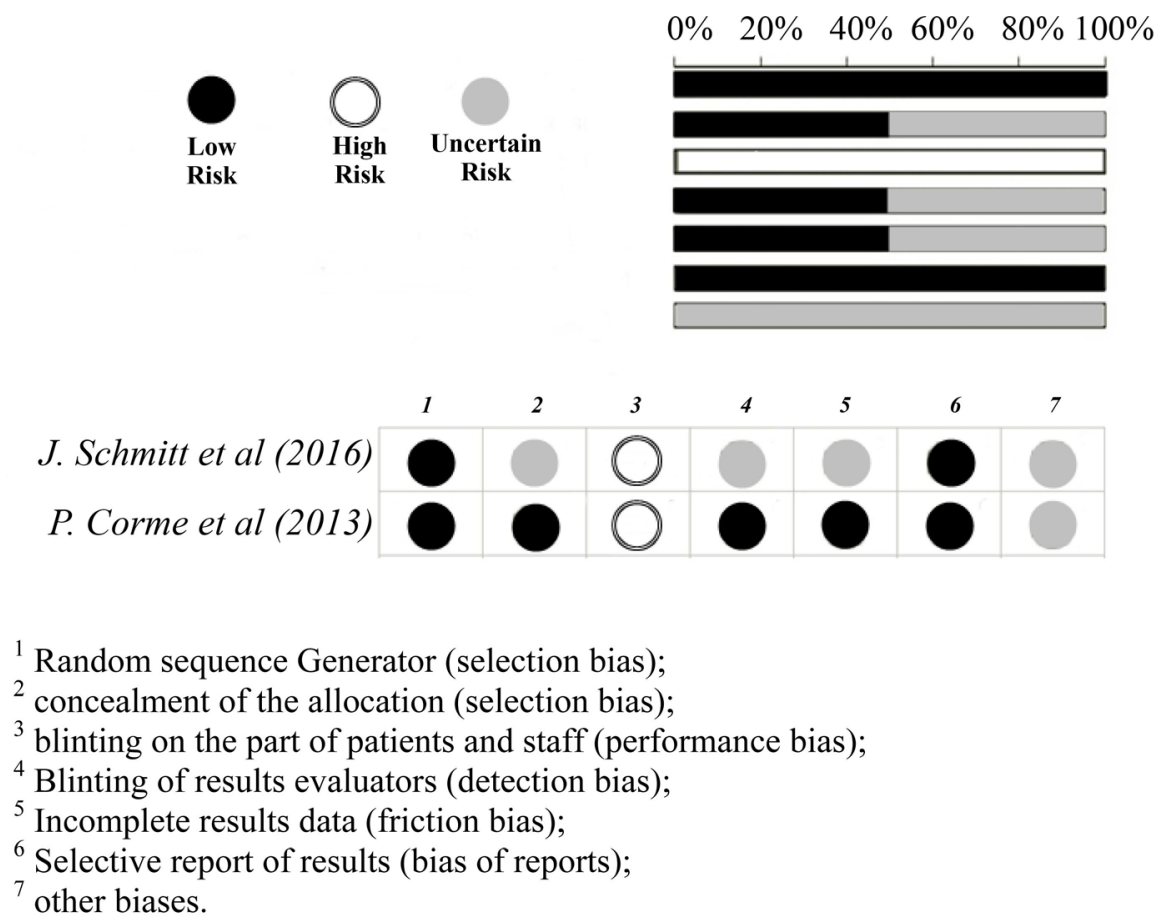

Figure 2. Risks of biases of the studies used.

\subsection{Statistical Analysis}

The effects of the interventions of the quality of life components were measured by the difference in means, standardized and grouped, by the random effects model and the meta package implemented in the software $R$ (version 3.3.2). Heterogeneity was assessed using the $Q$ statistic of Cochran and $\boldsymbol{P}^{2}$. The studies were considered heterogeneous when: $\boldsymbol{P}>50 \%$ and significance level $\mathrm{P}<0.05$, in this case, the reason for heterogeneity was explored.

\section{Results}

In the first selection, data were analyzed by means of the titles and abstracts and through this process, 26 articles from the PubMed database were selected. And in the second selection that also followed the procedure to analyze the titles and summaries of the articles contained in the data, the search resulted in only three articles from the database Bireme, totaling 29 articles selected for the full reading.

It is noteworthy that in the databases: Scielo and Lilacs The results of the 
searches were equivalent to zero academic texts. Proceeding with the procedures, after the selection and reading in full of the 29 academic studies, 27 articles were excluded, thus remaining only two texts that were included in this meta-analysis, as described in graphic details shown in Figure 3 (Flowchart of identification and selection of articles for systematic review).

It is important to report that in relation to the results of the permitted access articles there were no review studies of literature reviews of any specific modality (systematic, integrative, etc.), and that the discarded papers, 19 articles did not conform With the theme proposed by this research (in the case of high load and intensity exercises). Three were excluded from this research because of their

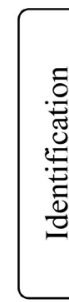

Studies identified in the databases:
PubMed $(\mathrm{n}=26)$ Lilacs $(\mathrm{n}=0)$ bireme $(\mathrm{n}=03)$ Scielo $(\mathrm{n}=0)$
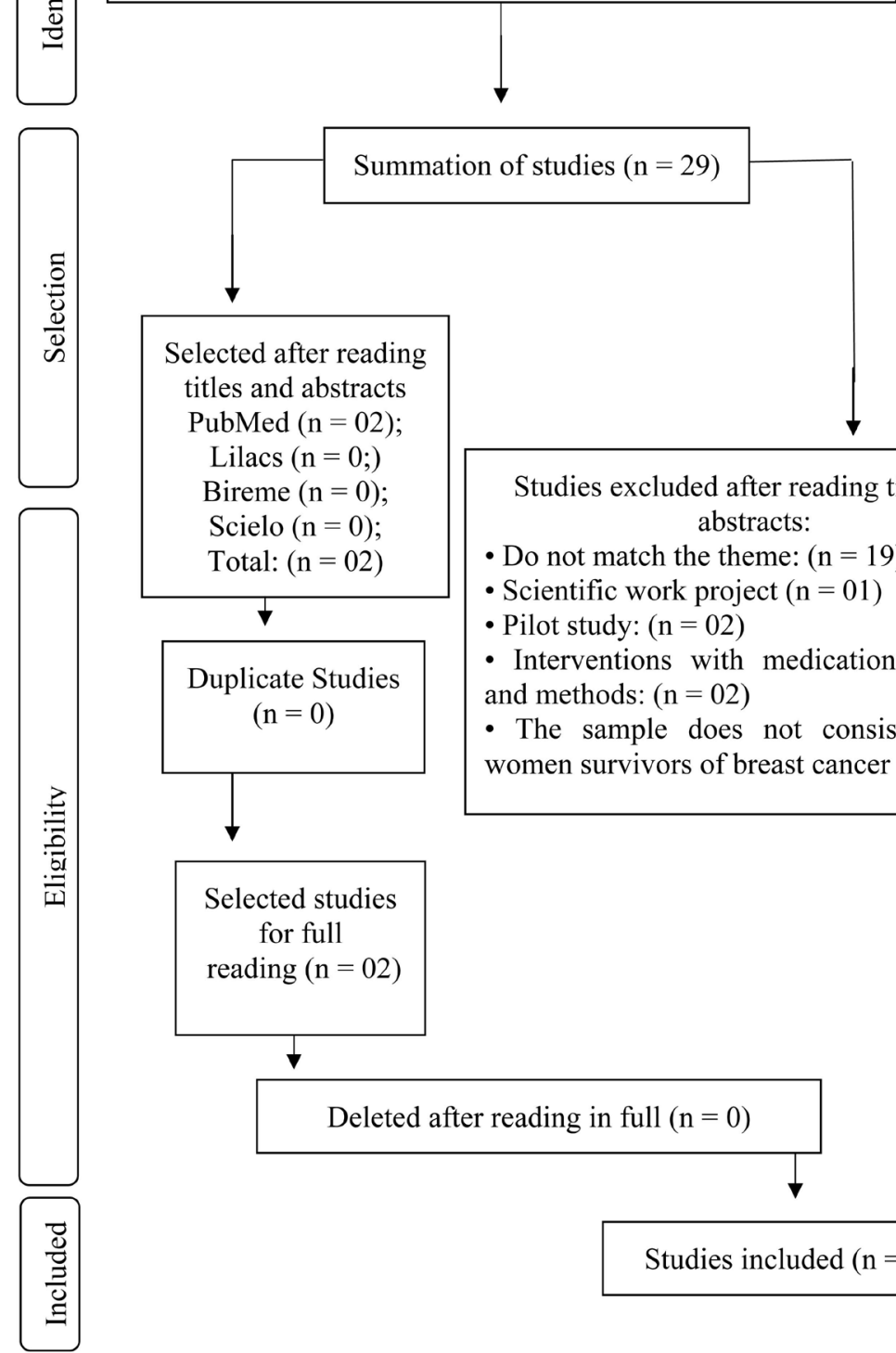

PubMed ( $\mathrm{n}=02)$; Lilacs $(\mathrm{n}=0$;) Bireme $(\mathrm{n}=0)$; Scielo $(\mathrm{n}=0)$ Total: $(\mathrm{n}=02)$

Studies excluded after reading titles and abstracts:

- Do not match the theme: $(\mathrm{n}=19)$

- Scientific work project $(\mathrm{n}=01)$

- Pilot study: $(n=02)$

Duplicate Studies $(\mathrm{n}=0)$

- Interventions with medication exercises and methods: $(\mathrm{n}=02)$

- The sample does not consist only of women survivors of breast cancer $(n=03)$

Figure 3. Identification flowchart and selection of articles for systematic review. 
study design that did not corroborate the inclusion criteria described earlier in the methodology of this review, two more were not used because they did interventions with exercises in parallel with the use of pharmacological methods, and finally the last three among the 27 excluded studies, were dispensed by the fact that they did not present the samples composed exclusively by individuals who were affected by breast cancer (BC).

Thus, only two literary data were left that fit the criteria proposed by the theme and methodology of the present study. The studies used in this study had in common the evaluation data of essential components of quality of life in survivors of $\mathrm{BC}$ who performed high-intensity physical exercises; such data underwent a statistical procedure of Meta-analysis and were exposed in detail in Figure 4.

\section{Discussion}

Table 1 shows that in the first study we used an exercise protocol that made use of high loads between $75 \%$ and $85 \%$ of one repetition maximum ( $1 \mathrm{RM}$ ) versus low load exercises between $55 \%$ and $65 \%$ of $1 \mathrm{RM}$, for women survivors of Breast cancer (BC) with clinical diagnosis of Secondary lymphedema. We know that women who have undergone a surgical intervention due to $\mathrm{BC}$, tend to report the increase of symptoms including pain, heaviness, numbness and stiffness in the upper limb [16].

In addition, there is a considerable loss of muscle strength in the affected arm [17] [18]. And with the loss of strength come the limitations of biomechanical functions [19] [20]. The physical exercise, in particular, the training with external loads, is one of the most used strategies for the improvement of the biomechanical function through the increase or restructuring of the muscular strength [20] [21].

The treatment through training with external loads also contributes to the increase of lymphatic clearance through the natural effect of [22] [23] muscle pump. It is observed that the exercise performed with the lifting of higher loads

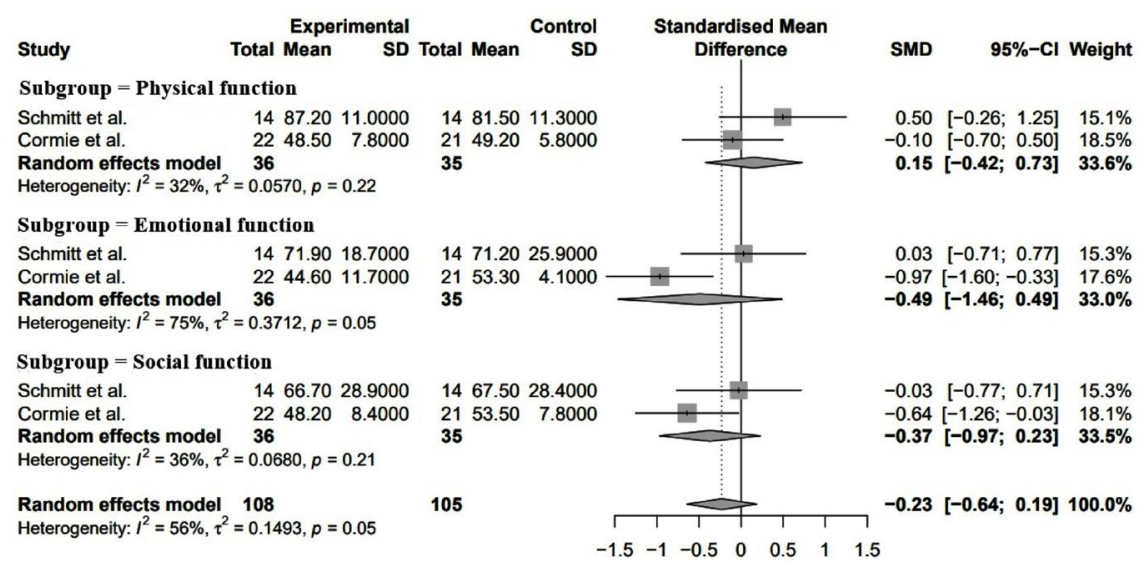

Figure 4. Forest Plot of the meta-analysis of the studies, of the components of quality of life: physical function; emotional function; and social function. 
Table 1. Characteristics of the studies of our results.

\begin{tabular}{|c|c|c|c|c|c|c|c|}
\hline Authors & $\begin{array}{c}\text { Title and } \\
\text { Descriptors }\end{array}$ & Year & Periodic & Sample & Type of Intervention & Results & Conclusions \\
\hline $\begin{array}{l}\text { P. Corme } \\
\text { et al. }\end{array}$ & $\begin{array}{l}\text { Title: Is it safe } \\
\text { and efficacious } \\
\text { for women with } \\
\text { lymphedema } \\
\text { secondary to } \\
\text { breast cancer to } \\
\text { lift heavy weights } \\
\text { during exercise: a } \\
\text { randomised } \\
\text { controlled trial. } \\
\text { Descriptors: } \\
\text { Resistance } \\
\text { exercise; } \\
\text { Weight-lifting; } \\
\text { Lymphedema; } \\
\text { Breast câncer; } \\
\text { Dose-response } \\
\text { relationship. }\end{array}$ & 2013 & $\begin{array}{l}\text { Journal of } \\
\text { Cancer } \\
\text { Survivorship, } \\
\text { Volume } 7, \\
\text { número } 3 \text {, } \\
\text { páginas } 413 \text { a } \\
424 \text {. }\end{array}$ & $\begin{array}{l}\text { N-Total: } 62 \\
\text { Characteristic: Women } \\
\text { surviving breast cancer } \\
\text { (BC), with a clinical } \\
\text { diagnosis of } \\
\text { lymphedema secondary } \\
\text { to CM of at least } 1 \text { year } \\
\text { before the study. } \\
\text { Average age: not } \\
\text { informed. } \\
\text { Groups: } \\
\text { i) high-load exercises } \\
\text { between } 75 \% \text { and } 85 \% \\
\text { of } 1 \text { RM ( } \mathrm{n}=22 \text { ); } \\
\text { ii) low-load resistance } \\
\text { exercises between } 55 \% \\
\text { and } 65 \% \text { of } 1 \mathrm{RM} \text { ( } \mathrm{n}= \\
21 \text { ); } \\
\text { iii) habitual care or } \\
\text { control group ( } \mathrm{n}=19 \text { ). }\end{array}$ & $\begin{array}{l}\text { Characteristic: High load } \\
\text { resistance exercise, versus low } \\
\text { load resistance exercise, versus } \\
\text { the usual care for the treatment } \\
\text { of lymphedema secondary to } \\
\text { breast cancer. } \\
\text { Total duration: } 3 \text { months. } \\
\text { Duration of sessions: not } \\
\text { informed. } \\
\text { Weekly charge: } 60 \text { min. } \\
\text { Process: Started with } 10 \text { min. - } \\
\text { heating; and ended with } 5 \\
\text { min.-Aerobic low intensity plus } \\
\text { stretching. } \\
\text { Exercises: Straight bench press, } \\
\text { front pull, lateral elevation, } \\
\text { direct thread, triceps extension, } \\
\text { cuff thread, knee extension, and } \\
\text { squat. }\end{array}$ & $\begin{array}{l}\text { Degree of lymphedema } \\
\text { between groups: There } \\
\text { was no difference in } \\
\text { swelling. } \\
\text { Severity of symptoms } \\
\text { among groups:There was } \\
\text { no difference in swelling. } \\
\text { In relation to the control } \\
\text { group, both of the } \\
\text { intervention groups } \\
\text { obtained: } \\
\text { + Quality of life; } \\
\text { + Physical function; } \\
\text { + Emotional function; } \\
\text { + Social function; } \\
+ \text { Strength; } \\
\text { + Muscular Endurance; + } \\
\text { functionality. }\end{array}$ & $\begin{array}{l}\text { Women survivors } \\
\text { of breast cancer } \\
\text { with lymphedema } \\
\text { can lift high loads } \\
\text { during resistance } \\
\text { exercise to the } \\
\text { upper body, } \\
\text { without fear of } \\
\text { exacerbation of } \\
\text { lymphedema or } \\
\text { increased severity of } \\
\text { symptoms. }\end{array}$ \\
\hline $\begin{array}{c}\text { J. Schmi } \\
\text { et al. }\end{array}$ & $\begin{array}{l}\text { Títule: } \\
\text { A 3-week } \\
\text { multimodal } \\
\text { intervention } \\
\text { involving } \\
\text { high-intensity } \\
\text { interval training } \\
\text { in female cancer } \\
\text { survivors: a } \\
\text { t randomized } \\
\text { controlled trial. } \\
\text { Descriptors: } \\
\text { Cancer survivors; } \\
\text { cardiorespiratory } \\
\text { fitness; energy } \\
\text { expenditure; } \\
\text { exercise; } \\
\text { rehabilitation; } \\
\text { sense wear. }\end{array}$ & 2016 & $\begin{array}{l}\text { Physiological } \\
\text { Reports, } \\
\text { volume } 4 \text {, } \\
\text { número } 3 \text {. }\end{array}$ & $\begin{array}{l}\text { N-Total: } 28 \\
\text { Characteristic: Women } \\
\text { surviving breast cancer } \\
\text { (BC) } \\
\text { Groups: } \\
\text { 1) Hiit ( } \mathrm{n}=14 \text { ); } \\
\text { ii) Low to moderate } \\
\text { intensity exercises ( } \mathrm{n}= \\
\text { 14). } \\
\text { Average age: } \\
\text { Group I) } \pm 53.8 \text {; } \\
\text { Group II) } \pm 54.9 \text {. } \\
\text { Group monitoring: } \\
\text { heart rate was } \\
\text { monitored telemetrically } \\
\text { (Polar, FS1c, Polar Oy, } \\
\text { Kempele, Finlândia). }\end{array}$ & $\begin{array}{l}\text { Characteristic: Multimodal } \\
\text { rehabilitation with HIIT and } \\
\text { low to moderate intensity } \\
\text { exercises. } \\
\text { Total Duration: } 3 \text { weeks. } \\
\text { Duration of sessions: Group I) } \\
12 \text { minutes; Group II) } 75 \\
\text { minutes. } \\
\text { Weekly load: } \\
\text { Group I) } 3 \text { HIIT sessions } \\
\text { (separated by at least } 24 \text { h); } \\
\text { Group II) } 2 \text { sessions per week. } \\
\text { Process: Group I) Heating of } 5 \\
\text { min. To } 70 \% \text { of the peak heart } \\
\text { rate; Group II) performed the } \\
\text { exercises at } 60 \% \text { of the heart } \\
\text { rate peak. } \\
\text { Exercises: Group I) outdoor } \\
\text { race (paved track), being } 1 \text { min } \\
\text { to } 95 \% \text { of the peak heart rate } \\
\text { for } 2 \text { min. slow interval; Group } \\
\text { II) outdoor hiking and biking. }\end{array}$ & 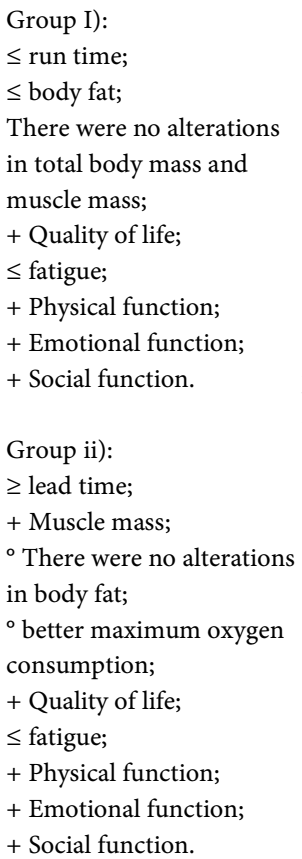 & $\begin{array}{l}\text { HIIT can be } \\
\text { performed by } \\
\text { female breast cancer } \\
\text { survivors, with no } \\
\text { adverse health } \\
\text { effects. }\end{array}$ \\
\hline
\end{tabular}

Legend: Studies filtered after systematic search in the databases cited in the methodology of this article.

between $70 \%$ and $95 \%$ of $1 \mathrm{RM}$, bring additional advantages in relation to the percentages of lower loads, the literature states that there is a relationship between the load response of the exercise of Strength and magnitude of gains in muscle structure and function [24] [25].

The results of the first study in Table 1 corroborated the physical evolution of CM survivors, considering that the group that performed the intervention between $75 \%$ and $85 \%$ of $1 \mathrm{RM}$, also presented higher gains in relation to the in- 
crease in the functionality of the force and muscular resistance when compared to the control group. It is noteworthy that the same occurred with the group that performed the interventions between $55 \%$ and $65 \%$ of $1 \mathrm{RM}$ and that no differences were found between the groups, in relation to the level of the swelling of the lymphedema and the other symptoms. In addition, a significant improvement in quality of life (QOL) was identified in the women studied.

Therefore, the results indicate that women surviving BC, (provided they are accompanied by a qualified and appropriate professional to perform interventions with physical exercises), even if they are lymphedema secondary to $\mathrm{BC}$, can make the use Low loads, and high in interventions for physical improvement and QOL. It is known that exercise is a beneficial and positive therapy for this population, whether it is applied during and or after the course of the disease, resulting in expressive clinically proven improvements, regardless of the intensity or type of exercise used in Intervention [26] [27].

Another reason to use the practice of exercises in treatment procedures or oncologic prevention is that cancer cells feed on energy reserves, which are stored in the human body in the form of adipose tissue [28]. For this reason, the adipose body mass potentializes the risks for the acquisition of various types of cancer, making it necessary to include regular physical exercise during the treatment process with the objective of decreasing and/or preventing the increase in the levels of Adiposity [29].

One of the training methods, which has been highlighted is the high intensity interval training known as HIIT (High intensity Interval Training), which in addition to showing good results in relation to its efficiency for body slimming [30], has become another tool to be used in the treatment of surviving women of BC.

In the results of the second article also contained in Table 1, we observe the use of a multimodal rehabilitation protocol, which made use of HIIT with intensity at $95 \%$ of the peak of the maximal heart rate and compared with the exercises of low to moderate intensity.

The group that performed the intervention with HIIT obtained body fat reduction, while in the low to moderate intensity group there were no changes in relation to this variable. Similar results are found in the study by Devin [31], who underwent intervention of four weeks of high-intensity exercise and identified improvements in both cardiorespiratory fitness and body composition of the studied sample, which was comprised of women surviving cancer.

Nowadays, it is evident in the literature that the use of high-intensity exercises is safe and effective in this population 15. The results of this study strengthen this fact, considering that the HIIT protocol brought positive data for quality of life, reduction of body fat and fatigue. Reinforcing this way, the exercise protocol of low to moderate intensity also promoted benefits for the group that performed it. Thus, HIIT can be used in women survivors of $\mathrm{BC}$ without risks to the quality of health, bringing the advantage of having a shorter chronological time of implementation of the Protocol when compared to the method of exercises of 
low to moderate intensity.

It is important to emphasize that women who experience the treatment of breast cancer present a great decline in QOL, especially in aspects that involve social and emotional life, which ends up affecting their functions of autonomy and biomechanics. Thus, general health impairment is observed, reducing the cardiorespiratory, metabolic, fitness and increase of body fat, being these risk factors predictors of the disease and quite detrimental to the success of the treatment [27] [28].

Being physically active, it brings several contributions to the QOL and acts in parallel in the prevention of various types of diseases [8]. Moreover, they have a positive influence on mood, improves body image and self-esteem, acting in this way in the reduction of the sequels and the physical and emotional symptoms experienced during the treatment of Cancer [32].

Figure 4 (Forest Plot of quality of life components: physical function; emotional function; and social function.), exposes the results of the QOL variables, that were analyzed in common by both of the studies used in this systematic review, and as we observe the meta-analysis it is observable that there was no statistical difference in relation to which type of intervention influence more in the improvement of physical functions, Emotional and social that make up the QOL. Thus, considering QOL, it is suggested that women who have undergone a process of breast cancer treatment may have improvements in the functions previously cited independently of the intensity and exercise protocol. Regarding the heterogeneity of the variables, it can be verified that the component emotional function presented $75 \%$ difference between the studies the reason for justifying this evidence can be explored through the use of distinct instruments in each study for the analysis of the emotional function component; By the difference in the number of participants in each sample due to the physical and emotional, psychological and biological individuality of the women studied and the different types of protocols used in physical exercise interventions.

On the reliability of the studies used in this study, Figure 2 (risks of biases of the studies used.), the data showing the final evaluation of the vises of the articles used in this research are contained, and both showed low credibility only In the "blinting" process by the samples used. These studies did not report whether there was such a procedure during the surveys, which clearly leaves the possible performance bias during the data collection phase. When analyzing each article in isolation as shown in Figure 2, it is perceived that in the content of author J. Schmitt et al., (2016), there is partially the selection and detection bias, while the work of P. Come et al., (2013), showed to be safer in these criteria more confidence for possible readers to reproduce the procedures described in their research.

Given the facts, it is worth highlighting that the bibliographic productions up to the present day in relation to the theme in question are scarce and the studies evaluating the relationship of physical exercise with treatment during or after 
cancer, have stated that interventions with the Physical exercise are beneficial, but the data of the publications are inconsistent with respect to volume or intensity, pillars of training prescription, to be recommended during interventions [33] [34]. And for safety precautions The scholars of the oncology area, encourage the use of simple exercises that simulate the activities of daily life, and that have mild and moderate intensities in order to avoid complications in the biomechanical health [13]-[35].

Despite this systematic review with meta-analysis eviding the effects of high-load exercise and high intensity on body health and quality of life during the treatment of breast cancer survivors (BCS), caution is suggested regarding their prescription, Current literature is still limited on the subject and because of this, there is still no favorable consensus regarding the prescription of intense exercise for BCS. It is necessary to further research to broaden the understanding of the effect of the practice of these exercises in BCS.

\section{Conclusion}

The studies used in this meta-analysis, pointed out that it is so safe and effective to use high-intensity exercises as moderate exercises in women survivors of breast cancer, and that in addition to ampliform the general quality of life the methods of high Intensity can also be used by health professionals to optimize the time of interventions, bringing a quality of benefits to improve resistance, muscle structure, maintenance of functionality, and contribute to a reduction Significant body fat, and in relation to physical, emotional and social functions related to quality of life, the data showed that there was no statistical difference between the use of mild to moderate and high intensities.

\section{Compliance with Ethical Standards}

The present study followed the international ethical principles for the production of a systematic review with meta-analysis, and was developed based on the PRISMA checklist [36]. And the protocol was registered priority at the International Prospective Register of Systematic Reviews (CRD42019107397), thus fulfilling all ethical precepts.

\section{Conflicts of Interest}

All authors declare that there are no conflicts of interest.

\section{References}

[1] Silva, C.B., Albuquerque, V. and Leite, J. (2010) Qualidade de vida em pacientes portadoras de neoplasia mamária submetidas a tratamentos quimioterápicos. Brazilian Research Cancerology, 56, 227-236.

[2] Brasil, Ministério da Saúde. Instituto Nacional do Câncer INCA (2011) Como se comportam as células cancerosas.

http://www.inca.gov.br/conteudo_view.asp?id=318 
[3] Ferlay, J., Autier, P., Boniol, M., Heanue, M., Colombet, M., Boye, P., et al. (2007) Estimates of the Cancer Incidence and Mortality in Europe in 2006. Annals of Oncology, 18, 581-592. https://doi.org/10.1093/annonc/mdl498

[4] Shimozuma, K., Ganz, P.A., Petersen, L., Hirji, K., et al. (2006) Quality of Life in the First Year after Breast Cancer Surgery: Rehabilitation Needs and Patterns of Recovery. Breast Cancer Research and Treatment, 56, 45-57. https://doi.org/10.1023/A:1006214830854

[5] World Cancer Research Fund; American Institute for Cancer Research (2007) Food, Nutrition, Physical Activity, and the Prevention of Cancer: A Global Perspective. American Institute for Cancer Research, Arlington, 342-393.

[6] Midtgaard, J., Christensen, J.F., Tolver, A., Jones, L.W., Uth, J., Rasmussen, B., et al. (2013) Efficacy of Multimodal Exercise-Based Rehabilitation on Physical Activity, Cardiorespiratory Fitness, and Patient-Reported Outcomes in Cancer Survivors: A Randomized, Controlled Trial. Annals of Oncology, 24, 2267-273.

https://doi.org/10.1093/annonc/mdt185

[7] Inumaru, L.E., Silveira, E.A. and Naves, M.M.V. (2011) Fatores de risco e de proteção para câncer de mama: Uma revisão sistemática. Cadernos de Saúde Pública, 27, 1259-1270. https://doi.org/10.1590/S0102-311X2011000700002

[8] Matsudo, S.M. (2006) Atividade física na promoção da saúde e QV no envelhecimento. The Revista Brasileira de Educação Física e Esporte, 20, 135-137.

[9] Ruddy, K.J., Stan, D.L., Bhagra, A., Jurisson, M. and Cheville, A.L. (2017) Alternative Exercise Traditions in Cancer Rehabilitation. Physical Medicine and Rehabilitation Clinics, 28, 181-192. https://doi.org/10.1016/j.pmr.2016.08.002

[10] Eickmeyer, S.M., Gamble, G.L., Shahpar, S. and Do, K.D. (2012) The Role and Efficacy of Exercise in Persons with Cancer. $P M \& R, 4,874-881$. https://doi.org/10.1016/j.pmrj.2012.09.588

[11] Alexander, S., Minton, O., Andrews, P. and Stone, P. (2009) A Comparison of the Characteristics of Disease-Free Breast Cancer Survivors with or without CancerRelated Fatigue Syndrome. European Journal of Cancer, 45, 384-392. https://doi.org/10.1016/j.ejca.2008.09.010

[12] Bag, L.F. and Ferreira, E.L. (2010) Women with Cancer and Their Relationship with Physical Activity. Revista Brasileira de Ciência e Movimento, 18, 11-17.

[13] Wingate, L. (1985) Efficacy of Physical Therapy for Patients Who Have Undergone Mastectomies: A Prospective Study. Physical Therapy, 65, 896-900. https://doi.org/10.1093/ptj/65.6.896

[14] Molinaro, J., Kleinfeld, M. and Lebed, S. (1986) Physical Therapy and Dance in the Surgical Management of Breast Cancer: A Clinical Report. Physical Therapy, 66, 967-996. https://doi.org/10.1093/ptj/66.6.967

[15] Kampshoff, C.S., Chinapaw, M.J.M., Brug, J., Twisk, J.W.R., Schep, G., Niziel, M.R., et al. (2015) Randomized Controlled Trial of the Effects of High Intensity and Low-to-Moderate Intensity Exercise on Physical Fitness and Fatigue in Cancer Survivors: Results of the Resistance and Endurance Exercise after ChemoTherapy (REACT) Study. BMC Medicine, 13, 275. https://doi.org/10.1186/s12916-015-0513-2

[16] Moffatt, C.J., Franks, P.J., Doherty, D.C., Williams, A.F., Badger, C., Jeffs, E., et al. (2002) Lymphoedema: An Underestimated Health Problem. British Journal of Dermatology, Supplement, 147, 8.

[17] Hayes, S.C., Rye, S., Battistutta, D. and Newman, B. (2010) Prevalence of UpperBody Symptoms Following Breast Cancer and Its Relationship with Upper-Body 
Function and Lymphoedema. Lymphology, 43, 178-187.

[18] Hayes, S., Battistutta, D. and Newman, B. (2005) Objective and Subjective Upper Body Function Six Months Following Diagnosis of Breast Cancer. Breast Cancer Research and Treatment, 94, 1-10. https://doi.org/10.1007/s10549-005-5991-z

[19] Prestes, J., Foschini, D., Marchetti, P., Charro, M. and Tibana, R. (2016) Prescrição e periodização do treinamento de força em academias. Editora Manole, 2, 1-29.

[20] Liu, C.J. and Latham, N.K. (2009) Progressive Resistance Strength Training for Improving Physical Function in Older Adults. The Cochrane Database of Systematic Reviews, No. 3, 2759. https://doi.org/10.1002/14651858.CD002759.pub2

[21] Fleck, S.J. and Kraemer, W.J. (2017) Fundamentos do treinamento de força muscular. Artmed Editora, 4, 59-168.

[22] Olszewski, W.L. and Engeset, A. (1980) Intrinsic Contractility of Prenodal Lymph Vessels and Lymph Flow in Human Leg. American Journal of Physiology-Heart and Circulatory Physiology, 39, 775-783. https://doi.org/10.1152/ajpheart.1980.239.6.H775

[23] Gashev, A.A. (2002) Physiologic Aspects of Lymphatic Contractile Function. Annals of the New York Academy of Sciences, 979, 178-187. https://doi.org/10.1111/j.1749-6632.2002.tb04878.x

[24] Fry, A.C. (2004) The Role of Resistance Exercise Intensity on Muscle Fibre Adaptations. Sport Medicine, 34, 663-679. https://doi.org/10.2165/00007256-200434100-00004

[25] Seynnes, O., Fiatarone, S.M.A., Hue, O., Pras, P., Legros, P. and Bernard, P.L. (2004) Physiological and Functional Responses to Low-Moderate versus High-Intensity Progressive Resistance Training in Frail Elders. The Journals of Gerontology Series A: Biological Sciences and Medical Sciences, 59, 503-509. https://doi.org/10.1093/gerona/59.5.M503

[26] Schmitz, K.H., Courneya, K.S., Matthews, C., Demark-Wahnefried, W., Galvão, D.A., Pinto, B.M., et al. (2010) American College of Sports Medicine Roundtable on Exercise Guidelines for Cancer Survivors. Medicine \& Science in Sports \& Exercise, 42, 1409-1426. https://doi.org/10.1249/MSS.0b013e3181e0c112

[27] Courneya, K.S. and Friedenreich, C.M. (2010) Physical Activity and Cancer: An Introduction. In: Physical Activity and Cancer, Springer, Berlin, 1-10. https://doi.org/10.1007/978-3-642-04231-7_1

[28] Fong, D.Y., Ho, W.J., Hui, B.P., Lee, A.M., Macfarlane, D.J., Leung, S.S., et al. (2012) Physical Activity for Cancer Survivors: Meta-Analysis of Randomised Controlled Trials. BMJ, 344, 70. https://doi.org/10.1136/bmj.e70

[29] Glaner, M.F. (2003) Importância da aptidão física relacionada à saúde. The Revista Brasileira de Cineantropometria e Desempenho Humano, 5, 75-85.

[30] Mundt, M.P. and Bertolini, E.L. (2016) Eficiência do HIIT comparado ao exercício moderado contínuo voltado ao emagrecimento. Anais do Evinci-Uni Brasil, 2, 101.

[31] Devin, J.L., Sax, A.T., Hughes, G.I., Jenkins, D.G., Aitken, J.F., Chambers, S.K., et al. (2016) The Influence of High-Intensity Compared with Moderate-Intensity Exercise Training on Cardiorespiratory Fitness and Body Composition in Colorectal Cancer Survivors: A Randomised Controlled Trial. Journal of Cancer Survivorship, 10, 467-479. https://doi.org/10.1007/s11764-015-0490-7

[32] Saço, L.F. and Ferreira, E.L. (2010) Mulheres com câncer e sua relação com a atividade física. Revista Brasileira de Ciência e Movimento, 18, 11-17.

[33] Meneses, E.J.F., González, J.E. and Ramírez, V.R. (2015) Effects of Supervised Mul- 
timodal Exercise Interventions on Cancer-Related Fatigue: Systematic Review and Meta-Analysis of Randomized Controlled Trials. Biomed Research International, 2015, Article ID: 328636. https://doi.org/10.1155/2015/328636

[34] Tian, L., Lu, H.J., Lin, L. and Hu, Y. (2016) Effects of Aerobic Exercise on Cancer-Related Fatigue: A Meta-Analysis of Randomized Controlled Trials. Supportive Care in Cancer, 24, 969-983. https://doi.org/10.1007/s00520-015-2953-9

[35] Archer, T., Fredriksson, A., Schütz, E. and Kostrzewa, R.M. (2011) Influence of Physical Exercise on Neuroimmunological Functioning and Health: Aging and Stress. Neurotoxicity Research, 20, 69-83. https://doi.org/10.1007/s12640-010-9224-9

[36] Galvão, T.F., Pansani, T.S.A. and Harrad, D. (2015) Principais itens para relatar Revisões sistemáticas e Meta-análises: A recomendação Prisma. Epidemiologia e Serviços de Saúde, 24, 335-342. https://doi.org/10.5123/S1679-49742015000200017

\section{Supplementary Information}

The production of the methodology to be used for the synthesis of meta-analysis counted on the participation of all authors, and following the procedures Almeida Neto, Araújo and Barbosa were responsible for the searches of the studies used in Systematic review, Carmo Silva, Cesário and Lima, were responsible for reproducing the search based on the methodology to confer the reproducibility of the study and both arrived in similar results, Lima, Araújo and Cesário tabulation of the data used And then Carvas Júnior was responsible for the statistical analysis and organization of the results, Canário was responsible for the introduction of the study, and together with Almeida Neto, Cesário, Barbosa and Carmo Silva held the discussion. All seven authors participated in the analysis of the risks of biases, the recommendations and limitations of the study and the conclusion based on the results obtained. 